\title{
DEVELOPMENT OF TECHNOLOGY FOR MANUFACTURING HARDWARE AND INTELLIGENT LEVELS OF THE SERVICE AUTONOMOUS MOBILE ROBOT AMUR-307
}

\author{
Alena V. Bogdanovich, Kirill B. Kirsanov, Roman V. Khelemendik, \\ Valentin E. Pryanichnikov \& Evgeny A. Prysev
}
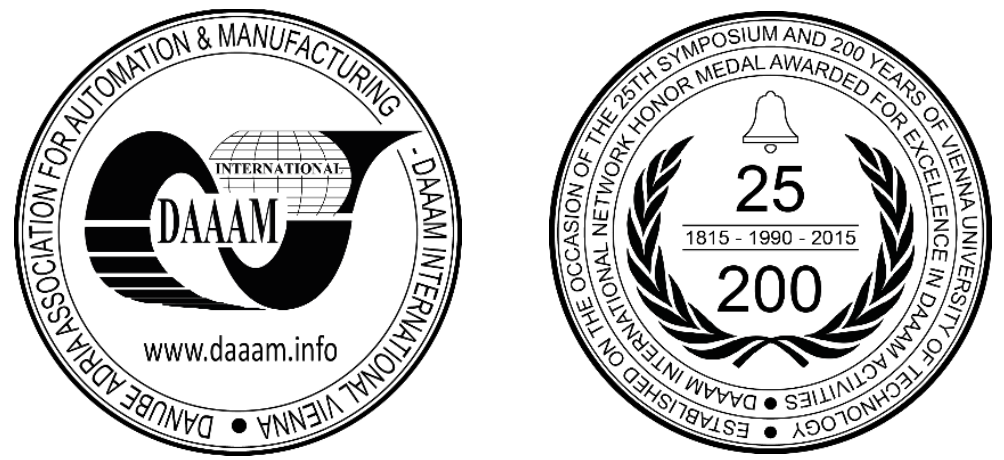

This Publication has to be referred as: Bogdanovich, A[lena]; Kirsanov, K[irill]; Khelemendik, R[oman]; Pryanichnikov, V[alentin] E. \& Prysev, E[vgeny] (2018). Development of Technology for Manufacturing Hardware and Intelligent Levels of the Service Autonomous Mobile Robot AMUR-307, Proceedings of the 29th DAAAM International Symposium, pp.1313-1318, B. Katalinic (Ed.), Published by DAAAM International, ISBN 978-3-902734-20-4, ISSN 1726-9679, Vienna, Austria DOI: $10.2507 / 29$ th.daaam.proceedings.189

\begin{abstract}
The article presents the results of the development of the main systems of autonomous caterpillar service mobile robot AMUR-307. A variant of the technology of manufacturing the mobile robot with manipulator, is based on the perspective layout, ease of assembly, features of dynamic stability, as well as on the basis of the price policy of production, industrial design criteria and areas of future application of such robots. The technology of construction of hardware and intellectual levels of distributed information-measuring and control systems for autonomous and supervisory mobile groups of such robots, including for work in extreme conditions. The paper was partially supported by RFBR, projects 16-07-00935, 1607-01264, 16-07-00811.
\end{abstract}

Keywords: robotics; service autonomous tracked mobile robots; industrial design; distributed information and control systems

\section{Introduction}

At the present time the investigations and development of autonomous mobile robots (AMR), created for various purposes and operating environments, including the training aims and organizing the networks of robotariums, are widely provided [1-14]. Unfortunately, it is quite difficult to produce a high-tech AMR, equipped with the latest technologies, while remaining within an acceptable cost. Therefore, it was necessary to develop an economical technology for the manufacture and assembling of the AMUR-307 robot, which became the basic platform for the development of structural solutions, and for the creation of promising distributed AMR control systems. In order to achieve this final goal, it is necessary to determine the possibilities of production, materials of manufacture, etc. Even more difficult is the problem of creating an effective technology for building hardware and software intelligent levels of distributed informationmeasuring and control systems, applicable for both autonomous and supervisory mobile groups of such robots, including for working in extreme conditions, and for industrial applications, that use joint work of hundreds and thousands of mechatronic devices. 


\section{Development of Autonomous mobile Universal Robot series AMUR}

Initially, on the stage of 3D-modeling and analysis of various forms of the main parts in terms of design, it was carried out the best ones. It was selected taking into account the criteria, related to the production capabilities, including the cost of implementation. For example, carrying out calculations, and checking in practice the operation of the gripper shown in Fig.1, it was decided to abandon it in favor of another design (Fig.2).

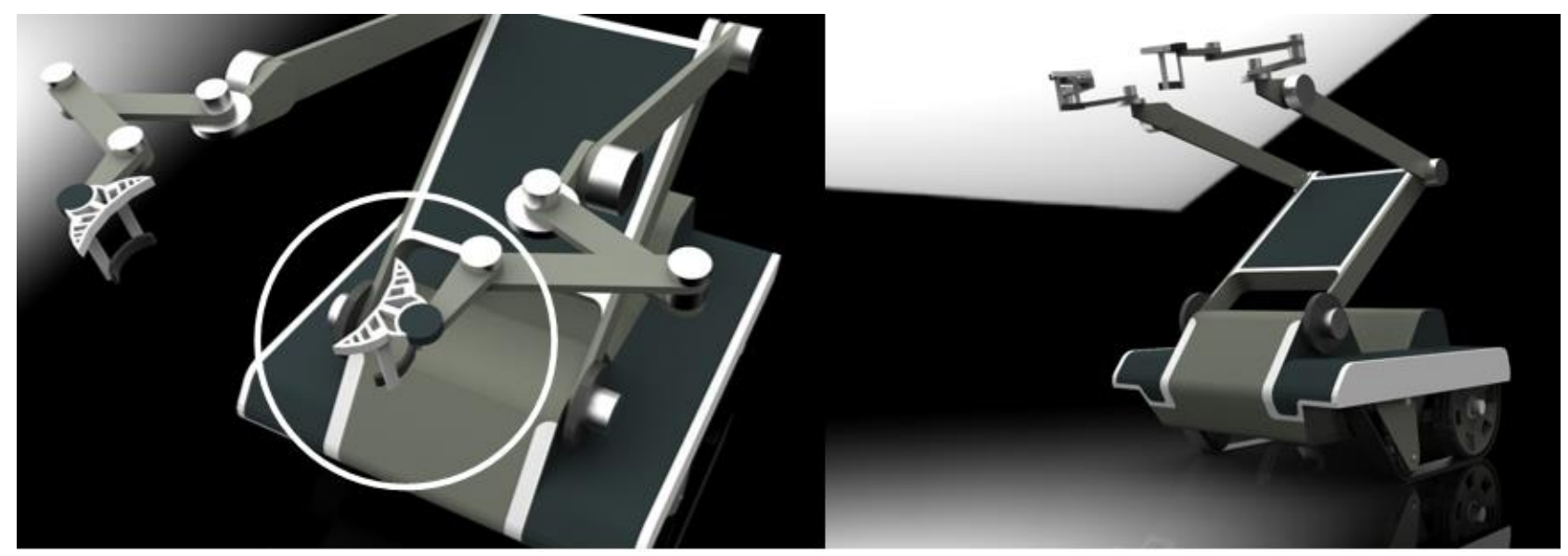

Fig. 1. The first simulated 3D versions

In the first model of the robot, the object is captured and held by two sponges. Closing of capture and maintenance of the necessary orientation of sponges is carried out by means of two mobile parts. Thus it is necessary to consider, that they are equal to each other and are connected kinematically. The design of the sponges and the constancy of their size, impose restrictions on the maximum and minimum diameter of the objects of manipulation, using two active fingers/tongs of the same design.

Unlike the first search model, which could capture the object of manipulation only by interacting simultaneously with two fingers, the implemented model of the gripper is able to interact both jointly and individually. The proposed scheme makes it possible to qualitatively increase the robot's ability to manipulate objects (for example, interaction with two objects at the same time), while maintaining the original functionality and the number of drives (Fig.2). To improve the characteristics of the griper, a tape is embedded on the inner surface of the "fingers" of the griper, which has a surface with an increased coefficient of friction.

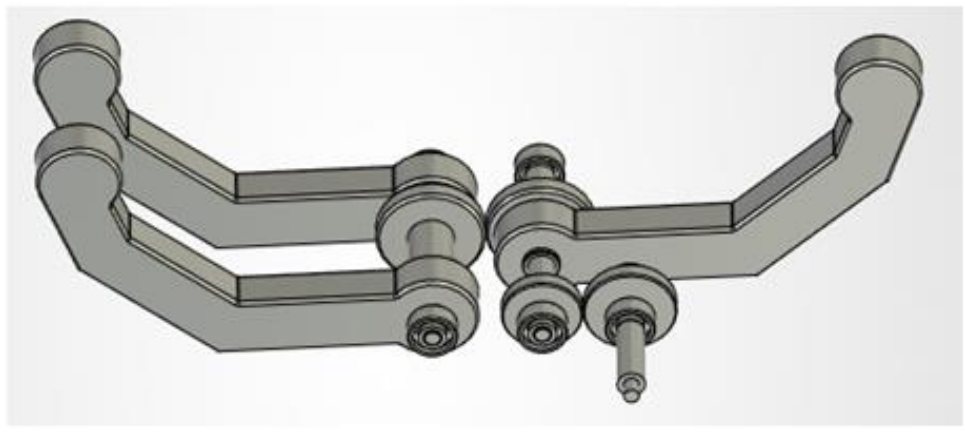

Fig. 2. The scheme of the fingers

Further, the approach to the development of the service robot body was changed, which led to a change in the internal layout of the main units. Changing the layout required a complete change of concept. As a result, a conceptual, layoutconstructive and design solution was developed for the AMUR - 307 service robot (a mobile platform with two-handed grippers). It was designed primarily for teaching students in higher educational institutions the basics knowledge in robotics in practice [2]. AMUR series robots are also applicable as service robots for various purposes and are the basic platform for testing both design solutions and for the creation of advanced distributed AMR control systems (Fig.3). On this model of the robot was tested a new technology of planar assembly of plastic sheets 300x600 mm (the maximum possible size for our standard laser-cutting machine) and 1.5-5 mm thick (Fig.4). Details of the body were cut on a laser machine, they do not require further processing, are lightweight, there the characteristics depend on the type of materials (in our case it's ABS plastic 5mm, acrylic glass $5 \mathrm{~mm}$, double-sided polystyrene $1.5-2 \mathrm{~mm}$ ). 

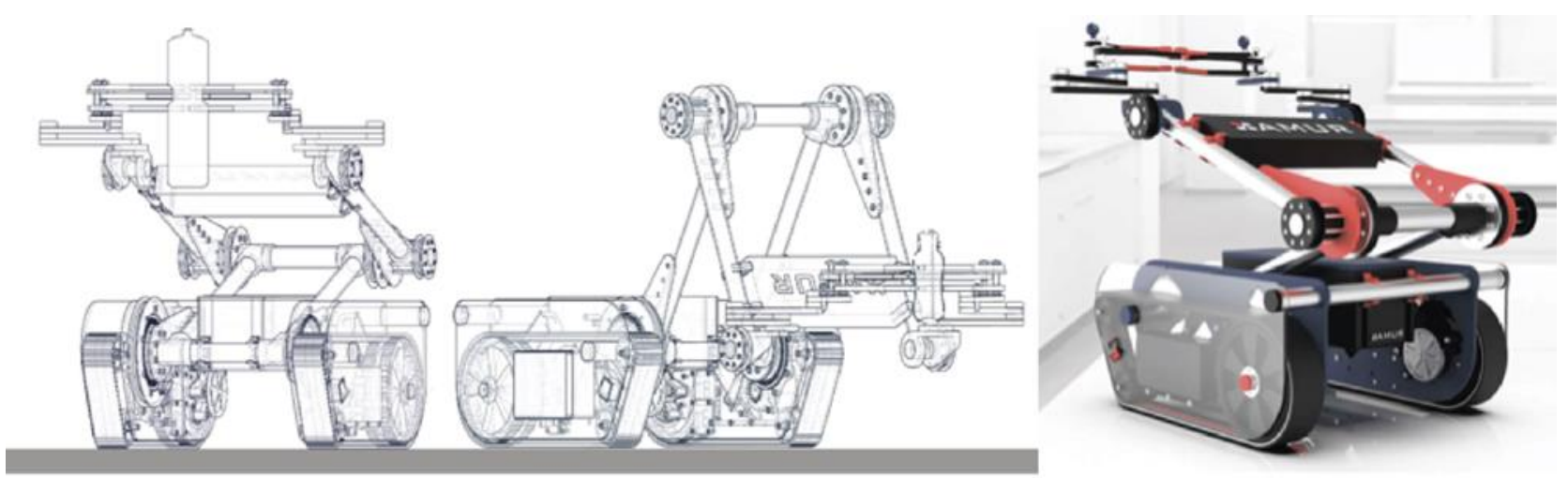

Fig. 3. Autonomous mobile universal robot AMUR-307

All the necessary technical elements of the robot are placed between four plates (two internal plates made of ABS plastic and two external ones made of acrylic glass), this solution helped to significantly increase the clearance and reduce the size and weight of the robot. When cutting, these plates are engraved with the layout of parts, which facilitates the assembly of the entire work.
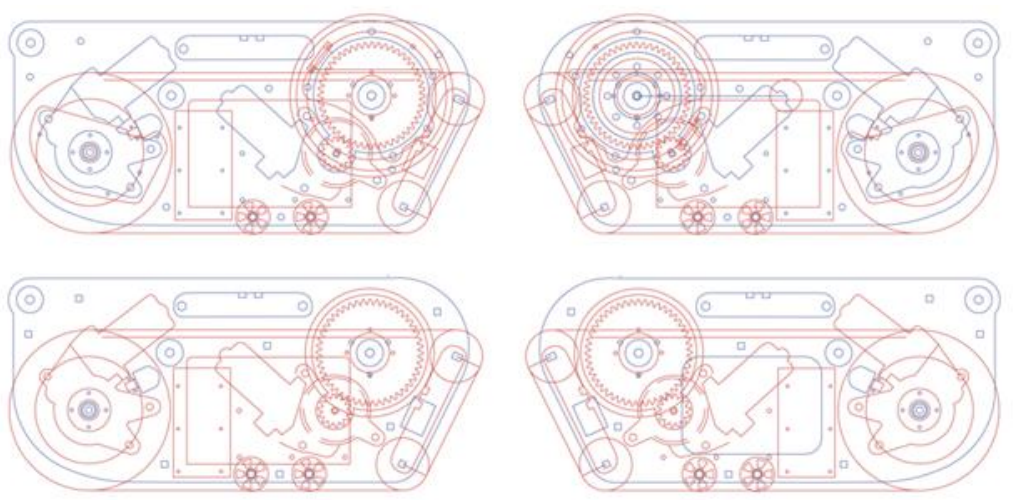

Fig. 4. Planar drawings for the laser-cutter machine

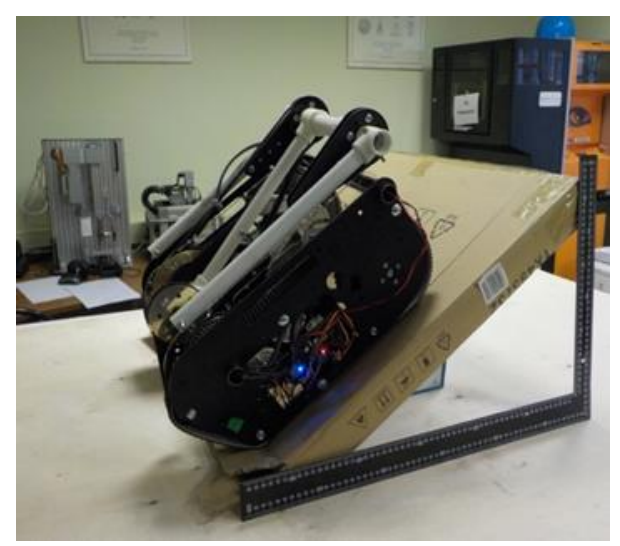

Fig. 5. Working model of AMR

A study of the static stability of the robot was carried out (Fig.3.5), which showed quite good results. It is planned to bring this idea to use in production, based on the wholesale purchase of technical parts, conveyor cutting of parts on laser cutting-machines and printing on 3D-printers.

\section{The development of the information-control system for robots AMUR-type}

Modern robotic systems, mobile robots and Industry 4.0 are software and hardware multi-level, heterogeneous control systems, in which are a large number of computing processes, interacting through a network. While there is a known problem of synchronization and establishment of the order of events, as well as the problem of reliability, extensibility, resistance to failure or planned shutdown of individual nodes, including mobile. In most applications, especially for extreme conditions, it is necessary to ensure the evolutionary development of the integrating software systems, it's restructuring work in changing production scenarios and implemented product recipes without stopping the operation with reliable logical analysis and blocking of failed situations. If for banking and office applications, such tasks were also set, then in robotics and in production with significantly more stringent requirements for real-time $(0.1-0.05$ seconds for decision-making), we do not know such statements. It was necessary to conduct a comprehensive fundamental research with a test of work on real equipment and in production to create the appropriate technology, methods of building such a highly relevant integrating, evolutionary software.

Depending on the implemented processes, the transmitted data in heterogeneous robotic systems have different priorities and requirements for bandwidth, latency, reliability, etc. For example, the CNC commands transmitted from the microcontroller to the actuators are very sensitive to delays and distortions, while the video signal from the surveillance cameras in the same production allows for very strong distortions and delays. As part of the development of Industry 4.0 and the Internet of Things, several new classes of tasks have appeared, with very specific requirements. One of these classes is a group of tasks related to the transmission, storage and processing of information and measurement data in heterogeneous systems. 
This class of problems is interesting primarily because it combines approaches developed in the framework of numerous studies of distributed computing networks, parallel and asynchronous programming and some approaches of developers of group control robots (for example, Taganrog works [14]).

There is a known problem of synchronization and establishment of the order of events, while building a multi-level heterogeneous system in which several computation processes occur. Classical algorithms for solving this problem are Lamport's Clock, Vector and Matrix clock. However, due to the presence of cycles in the computational graph, in a complex heterogeneous system, they are not applicable. To solve this problem, a deep variation of the Matrix clock algorithm is used, where a monotonically increasing counter is replaced by a 128-byte label compatible with UUID (ISO/IEC 11578:1996), where the higher bytes store the time with millisecond precision and the lower bytes store the random number assigned to this process. During the passage of each computing node of the system, this label, as well as the start time and duration of the process is appended to the message. When analyzing an array of such messages (for example, from a workshop with many hundreds of production mechtronique components), it becomes possible not only to diagnose current problems, but also to obtain an important metric of the system - such as throughput, latency, evaluation of system stability and the ability to extrapolate data to predict the occurrence of faults. However, such message enrichment is quite expensive in terms of data volume, so only binary compression protocols are used for data transmission. Our team has found key solutions to overcome these problems both at the lower level and at the level of intellectual management design, but there are still problems of an integration nature.

\section{Problems of distributed control and integration software}

The authors have implemented several projects to create integration software for distributed robotic groups (including EMERCOM of the Russian Federation) and big data processing systems with reliable backup for banking and industrial applications. In particular, it was tested the work with a mechanism of data transmission system Kafka, ensuring the correct operation of queues in a distributed environment with replication, and RDBMS - PosrgresSQL and time series database InfluxDB using ZooKeeper (Apache Zookeepper) service, which performs the role of a distributed service configuration and synchronization. This extensive experience in creating integration software, that dramatically improves the quality of complex software and hardware systems, has shown that it is necessary to conduct a systematic study in relation to robotics and to control thousands of real-time mechatronic devices and their virtual models (as one of the key tasks of Industry 4.0) in order to identify close to optimal software structures and data structures. The expected results here should lead us to a revolutionary change in the efficiency of robotic systems, primarily in the conditions of unreliability of communication channels, failure of individual units or erroneous actions of operators of supervisory control or incorrect interference of technologists in the process of controlling complex production processes. With the simultaneous launch of hundreds of computing processes, the identification of failures in their joint work and access to the appropriate logs with subsequent reconfiguration of the system is a complex programming and logical real-time task. Developed and tested by us approaches provide remote reprogramming of the main elements of the systems without stopping their operation with different admission to this developers, trained professionals or students and operating personnel, depending on their skills. This is supplemented by the system of parallel operation of virtual models and real multi-component mechatronic devices developed by us. Preliminary testing of such a system showed significantly higher efficiency (by more than an order of magnitude) in comparison with the well-known control systems (ROS etc.) for robots with various applications. Therefore, the further development of this approach, which requires its' fundamental research and analysis of options, should lead to even more significant results in parallel control of thousands of robots and mechatronic systems in real time.

We think, for the first time, it was suggested the task of creating integration software with the possibility of evolutionary extension, including remote reprogramming without stopping the operation of robots and complexes of mechatronic devices in real time, based on the features of programming languages. This is especially important in conditions of shortage of highly qualified specialists, capable of creating and operating such software and hardware systems, therefore, it is necessary to provide the possibility of operational intervention to prevent the negative consequences of failures, software errors in experimental systems, that are in the stage of debugging or trial production work, but do not allow stopping the production cycle. A similar problem arises when working in extreme conditions with the partial failure of communication channels, elements of sensor-control systems or mechatronic devices, which causes the restructuring of the control network with mobile nodes. Further development of this direction is supposed to be carried out on the basis of comprehensive testing in real conditions using the groupings of our mobile service robots of the AMUR-series and on real developments for the industry, which will lead to the construction of a new type of distributed mechatronic systems.

The experience we have in building real-time algorithms, that combine heuristic deduction and IGEC-technology, represents a unique opportunity to implement a new technology for working with robotic systems and industrial production by Industry type 4.0, applicable, for example, in the workshop for the production of innovative material TehFoam in Kimry (near Moscow), created with our participation, or to solve the problem of predictive calibration of mechatronic devices supplied by one of the concerns. Thus, the results of our comprehensive research of software and hardware systems, scalable data transmission and control systems in heterogeneous robotic systems are implemented in real, practical, urgent problems. 
The developed mechanism to support the ways of knowledge representation consists of 2 parts. First part is to work with logical formulas up to 1 billion characters in software systems, that implements the capabilities of the language of logic statements, provided means of optimization, storage, visualization, detailing, parallelization. Suggested optimization tools, in particular, allow us to minimize the number of sub-formulas, while translating formulas into the internal representation, which in practice leads to a significant reduction in time and memory overhead. Secondly, the proposed method of formalization / representation of real and supposed knowledge of experts for the construction of heuristic control algorithms (so-called "PentaLogics") opens us the possibility of forming effective software and hardware. The proposed methods and tools are used in specific implementations of Industry 4.0 projects, in the intellectualization of the service mobile robot Amur-307.

\section{Conclusion}

The proposed technology makes it possible to make the production of service, educational and other autonomous mobile robots acceptable in terms of price, which makes it possible to solve the problem of equipping educational institutions with the sets for practical classes in robotics (Robotariums), significantly increasing the level of practical knowledge of students. The use of the developed approaches to the creation of intelligent information-measuring and control systems of mobile robots ensures their high competitiveness and the possibility of parallel and remote operation both in the training mode and in the operation of robotic and industrial complexes. This also significantly increases the utilization of training equipment. The developed system of logging and storage of accumulated data provides unique opportunities for incident analysis and analysis of complex enterprise systems in real time

\section{Acknowledgments}

This paper was partially supported by the Russian Foundation for Basic Research, Project No. 16-07-01264a, 16-0700935a, 16-07-00811a

\section{References}

[1] V.E. Pryanichnikov, A.A. Aryskin, S.R. Eprikov, K.B. Kirsanov, R.V. Khelemendik, A.Ya. Ksenzenko, E.A. Prysev \& A.S. Travushkin (2017). Technology of Multi-Agent Control for Industrial Automation with Logical Processing of Contradictions, Proceedings of the 28th DAAAM International Symposium, pp.1202-1207, B. Katalinic (Ed.), Published by DAAAM International, ISBN 978-3-902734-11-2, ISSN 1726-9679, Vienna, Austria, DOI: 10.2507/28th.daaam.proceedings.167.

[2] Davydov, D.; Eprikov. S.; Kirsanov, K. \& Pryanichnikov, V. (2017). Service Robots Integrating Software 4nd Remote Reprogramming, Proceedings of the 28th DAAAM International Symposium, pp.1234-1240, B. Katalinic (Ed.), Published by DAAAM International, ISBN 978-3-902734- 11-2, ISSN 1726-9679, Vienna, Austria, DOI: 10.2507/28th.daaam.proceedings. 172

[3] Pryanichnikov, V.E.; Davydov, D.; Kirsanov, K. \& Eprikov, S. (2016). Programming of Robot Synergism in MultiAgent Simulators, Proceedings of the 27th DAAAM International Symposium, pp.0109-0115, B. Katalinic (Ed.), Published by DAAAM International, ISBN 978-3-902734- 08-2, ISSN 1726-9679, Vienna, Austria, DOI: 10.2507/27th.daaam.proceedings.016

[4] Pryanichnikov, V.; Ksenzenko, A.; Kuvshinov, S.; Poduraev, Y.; Prysev, E. \& Khelemendik, R. (2016). Intelligent Robotronics: Hardware-Software Complexes of Robotariums, Proceedings of the 27th DAAAM International Symposium, pp.0225-0229, B. Katalinic (Ed.), Published by DAAAM International, ISBN 978-3-902734-08-2, ISSN 1726-9679, Vienna, Austria, DOI: 10.2507/27th.daaam.proceedings.033

[5] Pryanichnikov V.E., Katalinic B., Kirilchenko A.A., Khelemendik R.V., Kuvshinov S.V., Vician D., Uglesic A. New Creative Educational Technologies for Inter-university Network // 25th DAAAM International Symposium on Intelligent Manufacturing and Automation. 2014. - Procedia Engineering. 2015. - Vol. 100, - P.259-268. - URL: http://www.sciencedirect.com/science/article/pii/S1877705815003938

[6] Pryanichnikov V.E., Biyelich T., Vitsan D., Katalinich B., Kirsanov K.B., Kuvshinov S.V., Marzanov Y.S., Podurayev Y.V., Khelemendik R.V., Prysev E.A., Ugleshik A., Kharin K.V. Development of education technologies and the network of associated laboratories-robotariums. Data Measuring and Control Systems, M.: Radioengineering, 2015, т.13, N7 - ISSN 2070-0814, P.7-25

[7] Pryanichnikov V.E., Khelemendik R.V. Information technology IGEC and Pentalogics // Computer Science and Information Technology: Materials of International Scientific Conf. - Saratov: The publication Centre "Science", 2016, pp. 331-333.

[8] V.E. Pryanichnikov, A.Ya. Ksenzenko, S.V. Kuvshinov, Yu.S. Marzanov, Yu.V. Podurayev, E.A. Prysev, R.V. Khelemendik, A.A. Aryskin, O.O. Belyayev, P.A. Bryzgalov, D.V. Davydov, D.A. Kuzovkin, P.F. Pletenev, S.R. Eprikov. Development of a network of robotariums and Amur mobile robots for innovative training in intelligent robotronics. // Proceedings of the International Multiconference - Network partnership in science, industry and education. - SPb: Company «Politekhnika-Service», - 2016, ISBN 978-5-906841-54-4, p.141-148. 
[9] Khelemendik R.V., Pryanichnikov V.E., On the building of a special logical language for the problems of intellectual robotics and the research of large formulas // Computer Science and Information Technology: Materials of International. Scientific Conf. - Saratov: The publication Centre "Science", 2018, pp. 425-428.

[10] V.E. Pryanichnikov, A.V. Bogdanovich, A.G. Zubov, A.V. Plotnikov, O.V. Punenkov. Development of the service autonomous mobile general-purpose robot AMUR-307// EXTREME ROBOTICS AND CONVERSION TENDENCIES. Abstracts of the International Scientific and Technological Conference. - SaintPetersburg: Company «Politekhnika-Print», 2018, pp.110-111(224 p).

[11] Kirillchenko A.A., Pryanichnikov V.E., Rogozin K.V. Limits of validity and reliability of proofs. Scepticism in mathematics, functions, and traditions // Information-Measuring and Control Systems. 2013. V. 11. № 4. P. $57-65$.

[12] Kirsanov K., Levinsky B., Pryanichnikov V. Integrating software for intelligent robots // Informational-Measuring and Control Systems, Radiotechnika. 2009. V. 7. № 6. P. 35-43.

[13] B. Katalinic, A.Ya. Ksenzenko, S.V. Kuvshinov, Yu.S. Marzanov, E.A. Pryisev, V.E. Pryanichnikov, R.V. Khelemendik, S.R. Epikov. The development of distributed software and hardware for «Robotariums» //EXTREME ROBOTICS. Proceedings of the International Scientific and Technological Conference. - Saint-Petersburg: «AP4Print», 2016, pp.459-460 (480 p.)

[14] Kaliaev I.A., Gaiduk A.R. Principles of Control by the Group of Objects, //"Mechatronics, automation, control", M.: New technologies.—- ISSN 1684-6427, №12, 2004, 80p. 